\title{
Mechanistic chemistry of oxidation of balsalazide with acidic chloramine-T and bromamine-T: A comparative spectrophotometric kinetic study
}

\author{
PUTTASWAMY* and S DAKSHAYANI \\ Department of Chemistry, Bangalore University, Central College Campus, Bangalore 560 001, India \\ e-mail: pswamy_chem@yahoo.com
}

MS received 26 October 2013; revised 15 March 2014; accepted 04 June 2014

\begin{abstract}
Balsalazide (BSZ) belongs to a class of non-steroidal anti-inflammatory drugs. Kinetics and mechanism of oxidation of BSZ with sodium N-halo-p-toluenesulfonamides viz., chloramine-T(CAT) and bromamine-T(BAT) in $\mathrm{HClO}_{4}$ medium have been spectrophotometrically investigated $\left(\lambda_{\max }=357 \mathrm{~nm}\right)$ at 303 $\mathrm{K}$. Under comparable experimental conditions, reactions with both the oxidants follow a first-order dependence of rate on [BSZ] and fractional-order dependence on each [oxidant] and $\left[\mathrm{HClO}_{4}\right]$. Activation parameters and reaction constants have been computed. 2-hydroxy-5-nitroso-benzoic acid and 3-(4-nitroso-benzoylamino)propionic acid are identified as the oxidation products of BSZ with both CAT and BAT. The rate of oxidation of BSZ is about five-fold faster with BAT than with CAT. Plausible mechanism and related rate law have been deduced for the observed kinetics.
\end{abstract}

Keywords. Balsalazide; chloramine-T and bromamine-T; oxidation-kinetics; mechanism.

\section{Introduction}

Balsalazide (BSZ), chemically known as (E)-5-[[-4[[2-carboxyethyl) amino] carbonyl] phenyl] azo]2-hydroxybenzoic acid, is a non-steroidal antiinflammatory $\operatorname{drug}^{1}$ (NSAID). It is available in the form of disodium dihydrate. It is useful for the treatment of ulcerative colitis and gastrointestinal disease. ${ }^{2} \mathrm{BSZ}$ is officially present in the United States Pharmacopoeia 2010. On account of its pharmaceutical applications, some of the analytical techniques have been reported in the literature for the estimation of BSZ in bulk drug and pharmaceutical dosage forms. ${ }^{3-6}$ But so far no research work has been carried out on the oxidation of this drug with any oxidants viewed from the kinetic and mechanistic viewpoints. The in vitro kinetic results would be very useful to kineticists who are working on the kinetic and mechanistic chemistry of BSZ drug in biological systems.

The chemistry of organic N-haloamines is of great interest due to their diverse chemical behaviour. ${ }^{7}$ The diverse nature of the chemistry of these compounds is due to their ability to act as halonium cations, hypohalite species and $\mathrm{N}$-anions, which act both as bases and nucleophiles. ${ }^{7}$ These compounds contain

*For correspondence positive halogen with +1 oxidation state which are mild oxidants. They interact with a wide range of functional groups, affecting a variety of molecular transformations. Review articles by Campbell and Johnson, ${ }^{7}$ Bremner, ${ }^{8}$ Banerji et al, ${ }^{9}$ Agarwal and Upadhyay, ${ }^{10}$ Amresto et $a l,{ }^{11}$ Geethanjali, ${ }^{12}$ Kolaveri et $a l^{13}$ and, very recently Jagadeesh and Puttaswamy ${ }^{14}$ comprehensively covered almost all the research work pertaining to the kinetic and mechanistic aspects of oxidation reactions of diverse group of substrates with organic $\mathrm{N}$-haloamines. The prominent member of this class of compounds is sodium N-chloro-ptoluenesulfonamide, commonly known as chloramine$\mathrm{T}$ (CAT; p- $\mathrm{CH}_{3} \mathrm{C}_{6} \mathrm{H}_{4} \mathrm{SO}_{2} \mathrm{NClNa} 3 \mathrm{H}_{2} \mathrm{O}$ ). It is a mild, efficient, stable, non-toxic and inexpensive oxidant, ${ }^{12}$ and hence the kinetic and mechanistic chemistry of this reagent have been well documented. ${ }^{8-14}$ Bromamine-T (BAT) is bromine analogue of CAT, which can be prepared easily by bromination of CAT. ${ }^{15}$ It has gained importance as an oxidant in acid and alkaline media. Although BAT is a better oxidant than CAT, not much attention has been paid, particularly on the kinetic and mechanistic aspects of oxidation of pharmaceuticals with this reagent. ${ }^{16-19}$ Hence, we thought of using CAT and BAT reagents for the oxidation of BSZ in order to compare their relative reactivities.

In view of the above facts, in the present communication, we report for the first time, the results of detailed 
investigations on the kinetic and mechanistic aspects of oxidation of BSZ by CAT and BAT in acid medium at $303 \mathrm{~K}$. The objective of the present research is mainly to unfold the mechanistic picture of BSZ-CAT/BAT redox system in acid medium through kinetic studies and to know the relative reactivity of BSZ drug towards CAT and BAT in acid medium.

\section{Experimental}

\subsection{Materials}

Chloramine-T was purchased from Merck and purified by the method of Morris et al. ${ }^{20}$ Bromamine-T was prepared as reported in the literature. ${ }^{15}$ Bromamine$\mathrm{T}$ was obtained by the partial debromination of dibromamine-T (DBT). To a solution containing $20 \mathrm{~g}$ CAT in $400 \mathrm{~mL}$ of water, about $4 \mathrm{~mL}$ of liquid bromine was added dropwise with constant stirring at room temperature. The solid DBT was filtered under suction washed thoroughly with ice cold water until all the absorbed bromine was removed and then vacuum-dried for $24 \mathrm{~h}$. About $20 \mathrm{~g}$ of DBT thus obtained was dissolved in $30 \mathrm{~mL}$ of $4 \mathrm{M} \mathrm{NaOH}$ with constant stirring at room temperature and the resultant aqueous solution was cooled in ice. Pale yellow crystals of BAT formed were separated out. They were filtered under suction, washed quickly with the minimum amount of water, and dried over $\mathrm{P}_{2} \mathrm{O}_{5}$. The purity of CAT and BAT was assayed iodometrically to determine the active halogen content. Aqueous solution of these oxidants was standardized by the iodometric method and stored in brown bottles to prevent photochemical deterioration. Pharmaceutical grade Balsalazide disodium dihydrate was kindly donated by Biocon Ltd., Bangalore, India. It was used as received and aqueous solution of the compound was prepared fresh just before use. Analytical grade chemicals and double distilled water was used throughout the research work.

\subsection{Kinetic measurement}

Kinetic runs were carried out using UV-Vis spectrophotometer (Digital spectrophotometer 166, Systronics, India). Raagaa Ultra Cold Chamber with digital temperature control (Chennai, India) was used to maintain the required temperature with $\pm 0.1{ }^{\circ} \mathrm{C}$ accuracy. Detailed kinetic runs were performed under pseudo-first-order conditions of [oxidant $]_{0}>>[\mathrm{BSZ}]_{0}$ at $303 \mathrm{~K}$. Reactions were carried out in glass stoppered pyrex boiling tubes whose outer surfaces were coated black to prevent photochemical effects. The oxidants as well as the requisite amounts of $\mathrm{BSZ}, \mathrm{HClO}_{4}$ solutions and water (to keep the total volume constant for all kinetic runs) taken in separate tubes were thermostatted at $303 \mathrm{~K}$ for $30 \mathrm{~min}$. The reaction was initiated by the rapid addition of a measured amount of oxidant to the stirred reaction mixture. Immediately, $4 \mathrm{~mL}$ of the reaction mixture was pipetted in to a cuvette placed in the UVVis spectrophotometer and absorbance measurements were made at $357 \mathrm{~nm}$ ( $\lambda_{\max }$ of BSZ) for more than two half-lives. The absorbance readings at $\mathrm{t}=0$ and $\mathrm{t}=\mathrm{t}$ are $\mathrm{D}_{0}$ and $\mathrm{D}_{\mathrm{t}}$. Plots of $\log \mathrm{D}_{0} / \mathrm{D}_{\mathrm{t}}$ vs. time were made to evaluate the pseudo-first-order rate constants $\left(\mathrm{k}^{/} \mathrm{s}^{-1}\right)$ which were found to be reproducible within $\pm 4-5 \%$. Regression coefficient $\left(\mathrm{R}^{2}\right)$ was calculated using fx-100Z scientific calculator.

\subsection{Reaction stoichiometry}

Reaction mixtures containing different ratios of oxidant (CAT or BAT) to BSZ were equilibrated at $303 \mathrm{~K}$ in presence of $4.0 \times 10^{-4} \mathrm{M} \mathrm{HClO}_{4}$ for $24 \mathrm{~h}$. Iodometric titrations of unreacted oxidant showed that one mole of BSZ consumed two moles of oxidant in both the cases confirming the following stoichiometry:

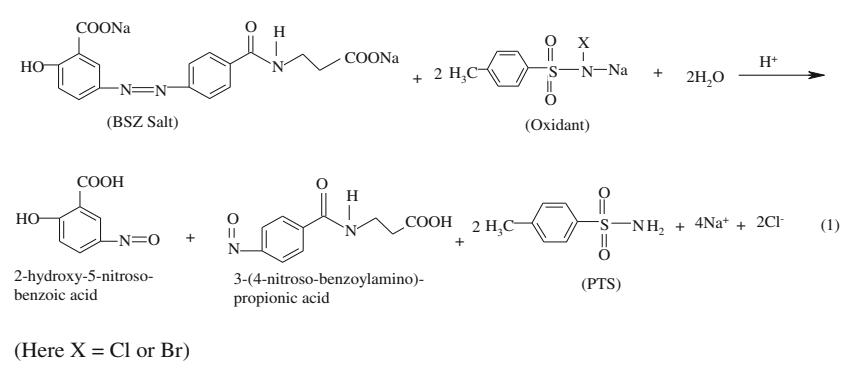

\subsection{Product characterization}

In the stoichiometric ratio, the reaction mixtures containing different concentrations of oxidant and substrate in $4.0 \times 10^{-4} \mathrm{M} \mathrm{HClO}_{4}$, under stirred condition, was allowed to react for $24 \mathrm{~h}$ at $303 \mathrm{~K}$ in both the cases. After completion of the reaction (monitored by thin layer chromatography), the reaction products were neutralized with base and extracted with ether. The organic products were subjected to spot tests and chromatographic analysis, which revealed the formation of 2-hydroxy-5-nitroso-benzoic acid and 3-(4-nitrosobenzoylamino)-propionic acid as oxidation products of BSZ and p-toluenesulfonamide (PTS) as the reduction product of the oxidants. The presence of these oxidation products was confirmed by LC-MS analysis. LCMS data were obtained by Time-of-flight mass spectrometry (TOFMS, Agilent, U.S.). The mass spectrum showed a molecular ion peak at 167 amu (figure 1) and 


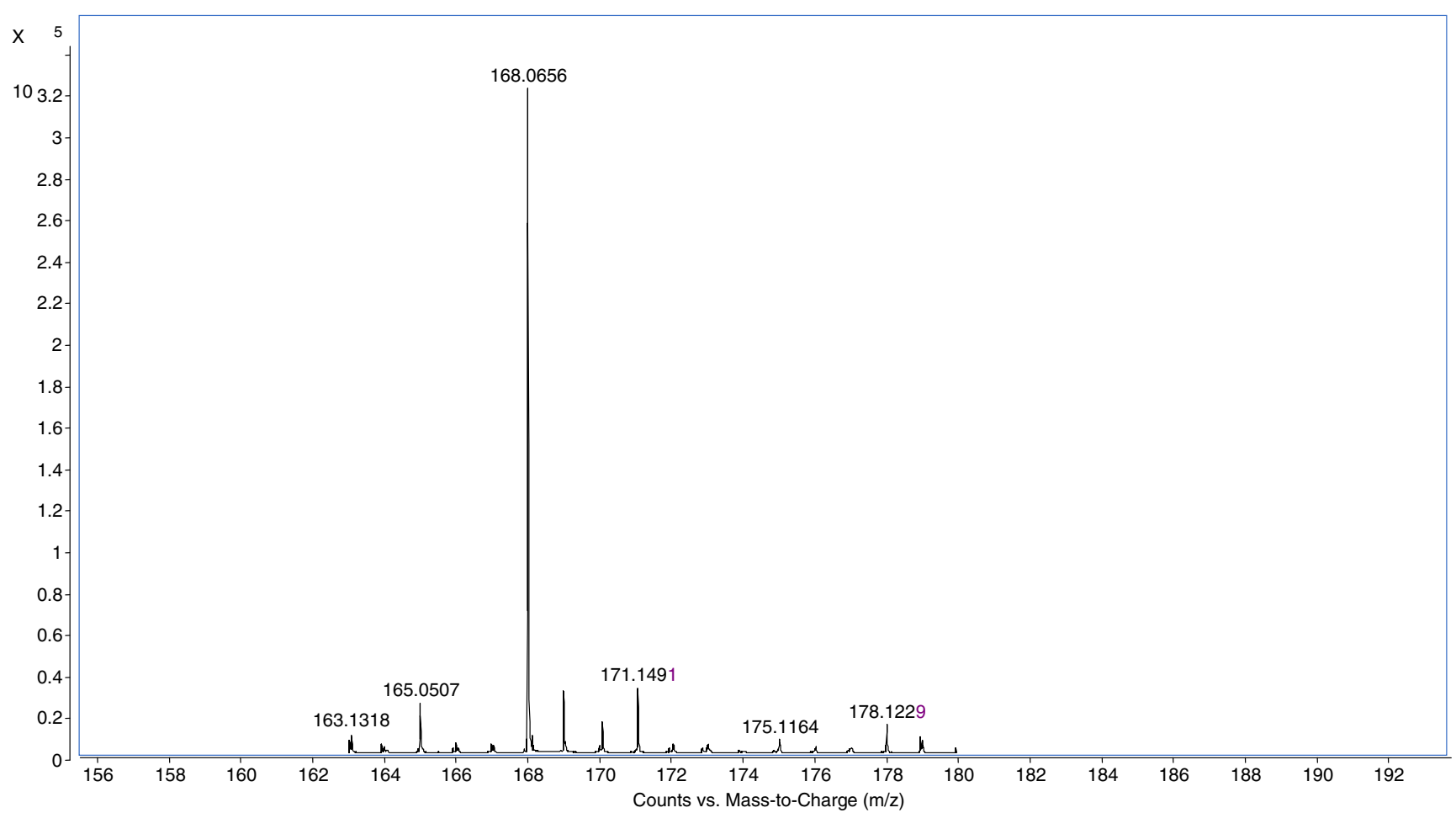

Figure 1. LC-MS of 2-hydroxy-5-nitroso-benzoic acid with its molecular ion peak at 167(M+1) amu.

222 amu (figure 2), clearly confirming 2-hydroxy-5nitroso-benzoic acid and 3-(4-nitroso-benzoylamino)propionic acid, respectively. Further, it was noticed that there was no reaction between these products and CAT or BAT under the present set of experimental conditions. PTS was extracted with ethyl acetate and detected by chromatography. ${ }^{16}$ Benzyl alcohol saturated with water was used as the solvent system, with $0.5 \%$ vanillin in $1 \% \mathrm{HCl}$ solution in ethanol as spray reagent $\left(\mathrm{R}_{\mathrm{f}}=0.905\right)$.

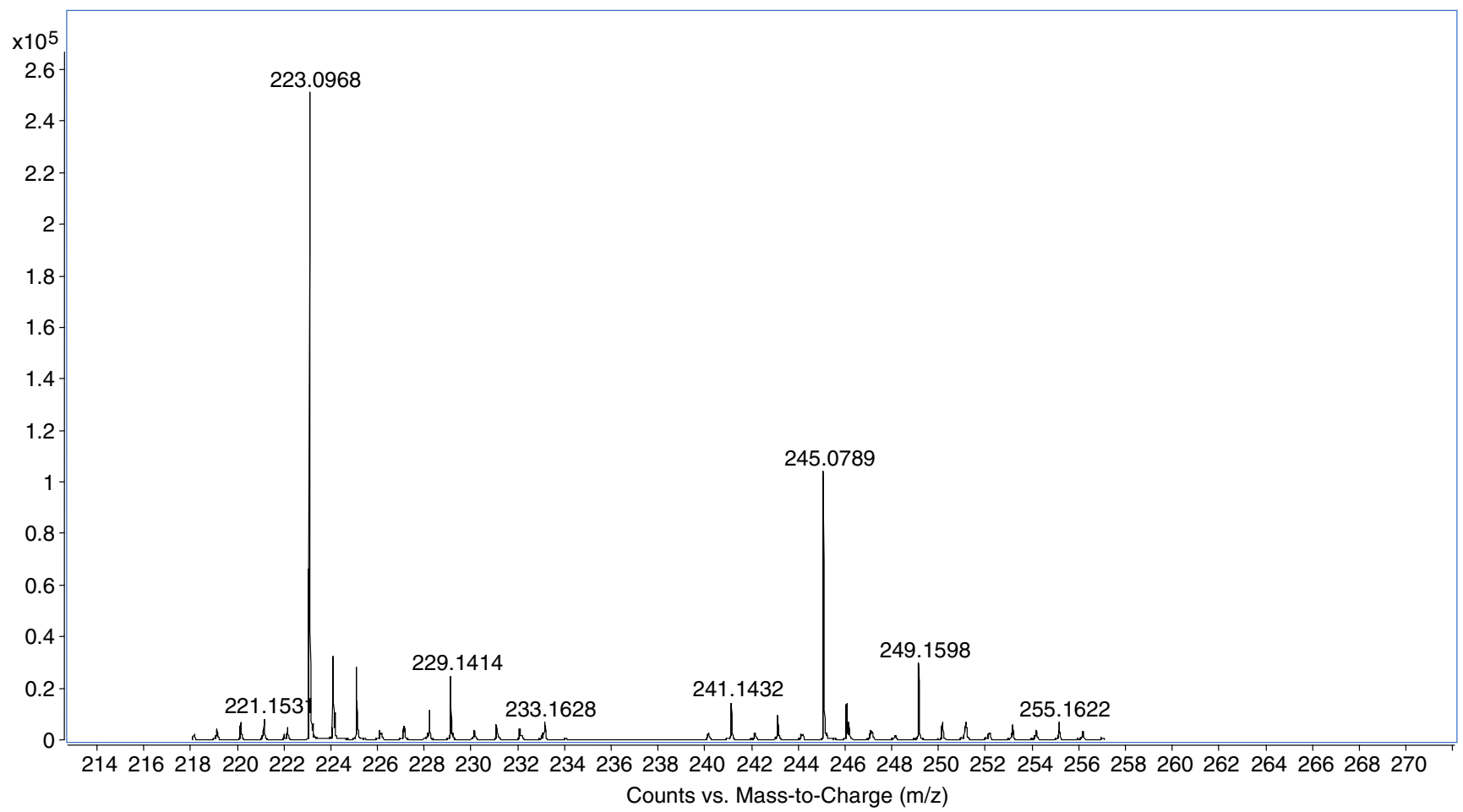

Figure 2. LC-MS of 3-(4-nitroso-benzoylamino)-propionic acid with its molecular ion peak at $222(\mathrm{M}+1) \mathrm{amu}$. 


\section{Results and Discussion}

The oxidation-kinetics of BSZ with CAT and BAT (henceforth CAT and BAT are labeled as oxidant) has been investigated at several initial concentrations of the reactants in acid medium at $303 \mathrm{~K}$. Under similar experimental conditions, the kinetic and mechanistic features are the same for the oxidation of BSZ with both CAT and BAT. But the relative rates of oxidation of BSZ with BAT are about five-fold faster than CAT.

\subsection{Effect of reactant concentrations on the reaction rate}

Under pseudo-first-order conditions of [oxidant $]_{0}$, $>>[\mathrm{BSZ}]_{0}$ at constant $[\text { oxidant }]_{0},\left[\mathrm{HClO}_{4}\right]$ and temperature, plots of $\log$ (absorbance) vs. time were linear $\left(\mathrm{R}^{2}>0.9853\right)$, indicating a first-order dependence of rate on $[\mathrm{BSZ}]_{0}$. The values of pseudo-firstorder rate constants $\left(\mathrm{k}^{/} \mathrm{s}^{-1}\right)$ were listed in table 1 . Further, $\mathrm{k}^{/}$did not vary with change in $[\mathrm{BSZ}]_{0}$, confirming the first-order dependence on $[\mathrm{BSZ}]_{0}$. Under the same experimental conditions, an increase in [oxidant $]_{0}$ led to an increase in the $\mathrm{k}^{\prime}$ values (table 1) and plots of $\log \mathrm{k}^{\prime}$ vs $\log$ [oxidant] $]_{0}$ were linear $\left(\mathrm{R}^{2}>0.9920\right)$ with slopes of 0.65 for CAT and 0.70 for BAT, showing a fractional-order dependence of rate on [oxidant $]_{0}$.

\subsection{Effect of $\mathrm{HClO}_{4}$ and PTS concentrations on the reaction rate}

The rate of the reaction increased with an increase in $\left[\mathrm{HClO}_{4}\right]$ (table 1$)$ and plots of $\log \mathrm{k}^{\prime}$ vs $\log \left[\mathrm{HClO}_{4}\right]$

Table 1. Effects of varying oxidant, substrate and acid concentrations on the reaction rate at $303 \mathrm{~K}$.

\begin{tabular}{lcccc}
\hline $10^{3}[\text { Oxidant }]_{\mathrm{o}}$ & $10^{4}[\mathrm{BSZ}]_{\mathrm{o}}$ & $10^{4}\left[\mathrm{HClO}_{4}\right]$ & \multicolumn{2}{c}{$10^{4} \mathrm{k}^{\prime} \mathrm{s}^{-1}$} \\
\cline { 5 - 6 } $\mathrm{M}$ & $\mathrm{M}$ & $\mathrm{M}$ & $\mathrm{CAT}$ & $\mathrm{BAT}$ \\
\hline 0.2 & 1.0 & 4.0 & 1.67 & 6.20 \\
0.5 & 1.0 & 4.0 & 3.80 & 15.3 \\
1.0 & 1.0 & 4.0 & 5.47 & 25.2 \\
2.0 & 1.0 & 4.0 & 8.06 & 36.7 \\
3.0 & 1.0 & 4.0 & 10.9 & 47.9 \\
1.0 & 0.4 & 4.0 & 5.35 & 25.3 \\
1.0 & 0.6 & 4.0 & 5.40 & 25.2 \\
1.0 & 1.0 & 4.0 & 5.47 & 25.2 \\
1.0 & 2.0 & 4.0 & 5.37 & 24.8 \\
1.0 & 4.0 & 4.0 & 5.49 & 25.1 \\
1.0 & 1.0 & 1.0 & 1.02 & 7.25 \\
1.0 & 1.0 & 3.0 & 3.98 & 19.9 \\
1.0 & 1.0 & 4.0 & 5.47 & 25.2 \\
1.0 & 1.0 & 5.0 & 6.40 & 31.4 \\
1.0 & 1.0 & 10.0 & 11.0 & 49.0 \\
\hline
\end{tabular}

were linear $\left(\mathrm{R}^{2}>0.9918\right)$ with slopes of 0.83 for CAT and 0.90 for BAT, showing a fractional-order dependence on $\left[\mathrm{HClO}_{4}\right]$. Addition of $4.0 \times 10^{-3} \mathrm{M} \mathrm{p}$ toluenesulfonamide (PTS) to the reaction mixture had no significant effect on the rate, suggesting that it is not involved in a pre-equilibrium to the rate-limiting step (rls).

\subsection{Effect of ionic strength on the reaction rate}

The influence of ionic strength (I) on the reaction rate was studied by adding $0.3 \mathrm{M} \mathrm{NaClO}_{4}$ solution to the reaction mixture. It was found that the ionic strength has negligible effect on the reaction rate. Hence, no attempt was made to keep the ionic strength of the medium constant during the kinetic runs.

\subsection{Effect of dielectric constant on the reaction rate}

In order to elucidate the nature of reactive species, the dielectric constant (D) of the solvent system was varied by adding methanol (0-20\% v/v) to reaction mixture, keeping other experimental conditions constant. The rate decreased with increase in the methanol content (table 2) and plots of $\log \mathrm{k}^{\prime}$ vs $1 / \mathrm{D}$ were linear (figure $3 ; \mathrm{R}^{2}>0.9891$ ) with negative slopes. The values of $\mathrm{D}$ for $\mathrm{MeOH}-\mathrm{H}_{2} \mathrm{O}$ mixtures reported in the literature ${ }^{21}$ were employed. Blank experiments showed that oxidation of methanol by CAT and BAT for the duration of the experiment were negligible.

\subsection{Effect of $\mathrm{NaCl}$ or $\mathrm{NaBr}$ concentration on the reaction rate}

Addition of $3.0 \times 10^{-3} \mathrm{M} \mathrm{NaCl}$ or $\mathrm{NaBr}$ solution to the reaction mixture had no effect on the rate, signifying that no inter-halogen or free chlorine or bromine is formed in the reaction sequence.

Table 2. Effect of varying dielectric constant of the medium on the reaction rate at $303 \mathrm{~K}$.

\begin{tabular}{lccc}
\hline$\% \mathrm{MeOH}$ & & \multicolumn{2}{c}{$10^{4} \mathrm{k}^{/} \mathrm{s}^{-1}$} \\
\cline { 3 - 4 }$(\mathrm{v} / \mathrm{v})$ & $\mathrm{D}$ & $\mathrm{CAT}$ & $\mathrm{BAT}$ \\
\hline 0 & 76.73 & 5.47 & 25.2 \\
5 & 74.50 & 4.87 & 23.6 \\
10 & 72.37 & 3.98 & 20.4 \\
20 & 67.48 & 2.01 & 16.6 \\
\hline
\end{tabular}

$[\text { Oxidant }]_{0}=1.0 \times 10^{-3} \mathrm{M} ;[\mathrm{BSZ}]_{0}=1.0 \times 10^{-4} \mathrm{M}$; $\left[\mathrm{HClO}_{4}\right]_{\mathrm{o}}=4.0 \times 10^{-4} \mathrm{M}$ 


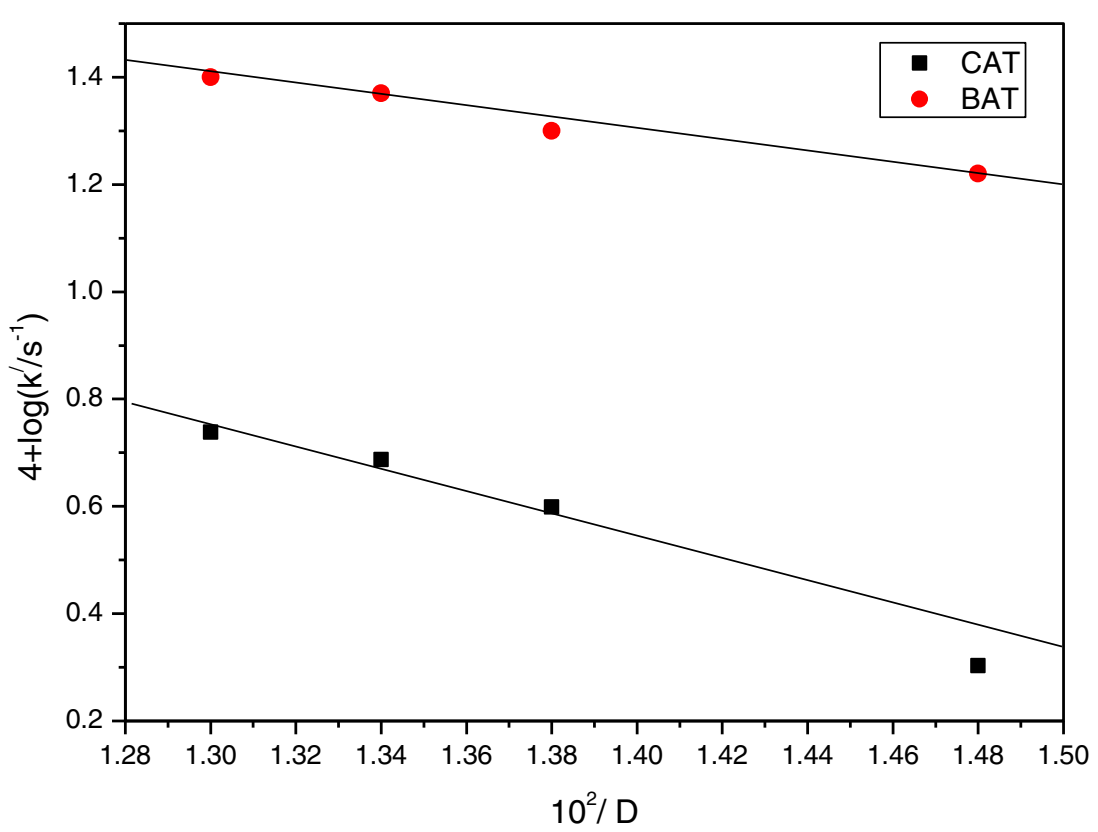

Figure 3. Plots of $\log \mathrm{k}^{/}$vs $1 / \mathrm{D}$.

\subsection{Test for free radicals}

Addition of reaction mixture to aqueous acrylamide solution does not initiate polymerization, demonstrating the absence of free radical species in the reaction sequence and ruling out the possibility of a free radical mechanism.

\subsection{Reactive oxidizing species}

Chloramine-T and bromamine-T are known to be mild oxidants in both acidic and alkaline media. ${ }^{7}$ In general, both CAT and BAT undergo two electron change in their reactions. ${ }^{22}$ The oxidation potential of CAT and BAT-PTS redox potential is $\mathrm{pH}$ dependent and it decreases with increase in $\mathrm{pH}$ of the medium. ${ }^{23}$ As CAT and BAT exhibit similar chemical properties, it is expected that identical equilibria exist in solutions of these compounds. Aqueous solutions of CAT and BAT act as strong electrolytes and they generate different types of reactive species, depending on $\mathrm{pH}$ of the medium. ${ }^{22}$ Investigations of Pryde and Soper, ${ }^{24}$ Morris et $a l,{ }^{20}$ Bishop and Jennings, ${ }^{22}$ and Hardy and Johnston $^{25}$ on organic N-haloamines have shown that similar equilibria exist in acid and alkaline solutions of these compounds. The possible equilibria in aqueous CAT and BAT solutions are:

$$
\begin{aligned}
& \text { TsNXNa } \rightleftharpoons \mathrm{TsNX}^{-}+\mathrm{Na}^{+} \\
& \mathrm{TsNX}^{-}+\mathrm{H}^{+} \rightleftharpoons \mathrm{TsNHX}
\end{aligned}
$$

$$
\begin{gathered}
\text { 2TsNHX } \rightleftharpoons \mathrm{TsNX}_{2}+\mathrm{TsNH}_{2} \\
\mathrm{TsNHX}+\mathrm{H}_{2} \mathrm{O} \rightleftharpoons \mathrm{TsNH}_{2}+\mathrm{HOX} \\
\mathrm{TsNX}_{2}+\mathrm{H}_{2} \mathrm{O} \rightleftharpoons \mathrm{TsNHX}+\mathrm{HOX} \\
\mathrm{HOX} \rightleftharpoons \mathrm{H}^{+}+\mathrm{OX}^{-} \\
\mathrm{HOX}+\mathrm{H}^{+} \rightleftharpoons \mathrm{H}_{2} \mathrm{O}^{+} \mathrm{X}
\end{gathered}
$$

(Here, Ts $=\mathrm{CH}_{3} \mathrm{C}_{6} \mathrm{H}_{4} \mathrm{SO}_{2}{ }^{-}$and $\mathrm{X}=\mathrm{Cl}$ for CAT and $\mathrm{Br}$ for BAT).

The possible oxidizing species in acidified CAT and BAT solutions are therefore TsNHX, $\mathrm{TsNX}_{2}, \mathrm{HOX}$, and $\mathrm{H}_{2} \mathrm{O}^{+} \mathrm{X}$. From these four possibilities, the reactive species of CAT and BAT can be decided based on the observed kinetic data. Since the involvement of $\mathrm{TsNX}_{2}$ as the reactive species predicts a second-order dependence of the rate on [oxidant $]_{0}$, which is contrary to the experimental observation, $\mathrm{TsNX}_{2}$ is ruled out as the oxidizing species. On the other hand, if HOX is primarily involved, a first-order retardation of the rate by added p-toluenesulfonamide $\left(\mathrm{TsNH}_{2}\right)$ is to be expected. Since no such effect is noticed, HOX can also be ruled out as the oxidizing species. Further, these two species are present in very low concentrations at the experimental conditions employed. Hardy and Johnston ${ }^{25}$ who have studied the $\mathrm{pH}$-dependent relative concentrations of the species present in acidified CAT solutions of comparable molarities, have shown that the conjugate 
acid is the likely oxidizing species. In view of the identical properties of CAT and BAT, similar argument can be extended to BAT also. Therefore, in the present investigations, TsNHX is assumed as the most probable oxidizing reactive species. Further, the substrate BSZ is a disodium salt. Hence, it is reasonable to assume that the disodium salt is fully ionized and completely dissociated to the corresponding di-anion $\left(\mathrm{S}^{2-}\right)$ which then undergoes reversible, double stage protonation equilibrium. Therefore $\mathrm{SH}_{2}$ is considered as the reactive substrate.

\subsection{Reaction scheme}

Based on the preceding discussion and kinetic results, the following reaction scheme is formulated for the oxidation of BSZ with CAT and BAT in acid medium:

The detailed mode of oxidation of BSZ with CAT and BAT is depicted in Scheme 2. In step (i) and (ii) of Scheme 2, the balsalazide dianion gets protonated in acid medium to give the balsalazide $\left(\mathrm{SH}_{2}\right)$. In the next fast step (iii), the BSZ reacts with TsNHX of oxidant to yield an intermediate complex I. This complex I in the next slow and rate-limiting step (step (iv)), hydrolyses to form an intermediate complex II with loss of $\mathrm{TsNH}_{2}$, followed by two fast steps. In the next step (step (v)), complex II reacts with another molecule of TsNHX to yield ultimate products after several fast steps.

\subsection{Deduction of rate law.}

From slow/rls of Scheme 1,

$$
\text { Rate }=\mathrm{k}_{4}[\text { Complex I] }
$$

If $[S]_{t}$ is the total effective concentration of substrate, then

$$
[\mathrm{S}]_{\mathrm{t}}=\left[\mathrm{S}^{2-}\right]+\left[\mathrm{SH}^{-}\right]+\left[\mathrm{SH}_{2}\right]+[\text { Complex I }]
$$

By steps (i), (ii) and (iii) of Scheme 1, the values of $\left[\mathrm{S}^{2-}\right],\left[\mathrm{SH}^{-}\right]$and $\left[\mathrm{SH}_{2}\right]$ are

$$
\begin{gathered}
{\left[\mathrm{S}^{2-}\right]=\frac{[\text { Complex I }]}{\mathrm{K}_{1} \mathrm{~K}_{2} \mathrm{~K}_{3}\left[\text { TsNHX] }\left[\mathrm{H}^{+}\right]^{2}\right.}} \\
\mathrm{S}^{2-}+\mathrm{H}^{+} \stackrel{\mathrm{K}_{1}}{\rightleftharpoons} \mathrm{SH}^{-} \\
\mathrm{SH}^{-}+\mathrm{H}^{+} \stackrel{\mathrm{K}_{2}}{\rightleftharpoons} \mathrm{SH}_{2} \\
\mathrm{SH}_{2}+\mathrm{TsNHX} \stackrel{\mathrm{K}_{3}}{\rightleftharpoons} \text { Complex I } \\
\text { Complex I } \stackrel{\mathrm{k}_{4}}{\longrightarrow} \text { Complex II } \\
\text { Complex II+ TsNHX } \longrightarrow \text { Products }
\end{gathered}
$$

$$
\begin{gathered}
{\left[\mathrm{SH}^{-}\right]=\frac{[\text { Complex I }]}{\mathrm{K}_{2} \mathrm{~K}_{3}[\text { TsNHX }]\left[\mathrm{H}^{+}\right]}} \\
{\left[\mathrm{SH}_{2}\right]=\frac{[\text { Complex I }]}{\mathrm{K}_{3}[\text { TsNHX }]}}
\end{gathered}
$$

By substituting for $\left[\mathrm{S}^{2-}\right],\left[\mathrm{SH}^{-}\right]$and $\left[\mathrm{SH}_{2}\right]$ from Eqs. 11, 12 and 13, respectively into Eq. 10, and solving for [Complex I], one obtains

\section{[Complex I]}

$$
=\frac{\mathrm{K}_{1} \mathrm{~K}_{2} \mathrm{~K}_{3}[\mathrm{TsNHX}][\mathrm{S}]_{\mathrm{t}}\left[\mathrm{H}^{+}\right]^{2}}{1+\mathrm{K}_{1}\left[\mathrm{H}^{+}\right]+\mathrm{K}_{1} \mathrm{~K}_{2}\left[\mathrm{H}^{+}\right]^{2}+\mathrm{K}_{1} \mathrm{~K}_{2} \mathrm{~K}_{3}[\mathrm{TsNHX}]\left[\mathrm{H}^{+}\right]^{2}}
$$

By substituting for [Complex I] from Eq. 14 into Eq. 9, the following rate law is obtained:

$$
\begin{aligned}
& \text { Rate } \\
& =\frac{\mathrm{K}_{1} \mathrm{~K}_{2} \mathrm{~K}_{3} \mathrm{k}_{4}[\mathrm{TsNHX}][\mathrm{S}]_{\mathrm{t}}\left[\mathrm{H}^{+}\right]^{2}}{1+\mathrm{K}_{1}\left[\mathrm{H}^{+}\right]+\mathrm{K}_{1} \mathrm{~K}_{2}\left[\mathrm{H}^{+}\right]^{2}+\mathrm{K}_{1} \mathrm{~K}_{2} \mathrm{~K}_{3}[\mathrm{TsNHX}]\left[\mathrm{H}^{+}\right]^{2}}
\end{aligned}
$$

Since the concentration of TsNHX corresponds to the concentration of oxidant (CAT or BAT), we can write Eq. 15 as

$$
\begin{aligned}
& \text { Rate } \\
& =\frac{\left.\mathrm{K}_{1} \mathrm{~K}_{2} \mathrm{~K}_{3} \mathrm{k}_{4} \text { [oxidant }\right][\mathrm{S}]_{\mathrm{t}}\left[\mathrm{H}^{+}\right]^{2}}{1+\mathrm{K}_{1}\left[\mathrm{H}^{+}\right]+\mathrm{K}_{1} \mathrm{~K}_{2}\left[\mathrm{H}^{+}\right]^{2}+\mathrm{K}_{1} \mathrm{~K}_{2} \mathrm{~K}_{3}[\text { oxidant }]\left[\mathrm{H}^{+}\right]^{2}}
\end{aligned}
$$

Rate law (16) satisfactorily fits well to the observed kinetic data wherein a first-order dependence of rate on $[\mathrm{S}]_{\mathrm{t}}$ and fractional-order on each [oxidant] and $\left[\mathrm{H}^{+}\right]$on the reaction rate was noticed. The values of equilibrium and decomposition constants were deduced as follows:

Since rate $=\mathrm{k}^{/}[\mathrm{S}]_{\mathrm{t}}$, under pseudo-first-order conditions of [oxidant $]_{0}>>[S]_{t}$, rate law (16) can be transformed as,

$$
\begin{aligned}
& \mathrm{k}^{\prime} \\
& =\frac{\left.\mathrm{K}_{1} \mathrm{~K}_{2} \mathrm{~K}_{3} \mathrm{k}_{4} \text { [oxidant }\right]\left[\mathrm{H}^{+}\right]^{2}}{\left.1+\mathrm{K}_{1}\left[\mathrm{H}^{+}\right]+\mathrm{K}_{1} \mathrm{~K}_{2}\left[\mathrm{H}^{+}\right]^{2}+\mathrm{K}_{1} \mathrm{~K}_{2} \mathrm{~K}_{3} \text { [oxidant }\right]\left[\mathrm{H}^{+}\right]^{2}}
\end{aligned}
$$

Scheme 1. A general reaction scheme for the oxidation of BSZ with CAT and BAT in acid medium. 


$$
\begin{aligned}
\frac{1}{\mathrm{k}^{\prime}} & \\
= & \frac{1}{\mathrm{~K}_{1} \mathrm{~K}_{2} \mathrm{~K}_{3} \mathrm{k}_{4} \text { [oxidant] }\left[\mathrm{H}^{+}\right]^{2}}+\frac{1}{\mathrm{~K}_{2} \mathrm{~K}_{3} \mathrm{k}_{4} \text { [oxidant] }\left[\mathrm{H}^{+}\right]} \\
& +\frac{1}{\left.\mathrm{~K}_{3} \mathrm{k}_{4} \text { [oxidant }\right]}+\frac{1}{\mathrm{k}_{4}} \\
\frac{1}{\mathrm{k}^{\prime}} & \frac{1}{[\text { oxidant }]}\left\{\frac{1}{\mathrm{~K}_{1} \mathrm{~K}_{2} \mathrm{~K}_{3} \mathrm{k}_{4}\left[\mathrm{H}^{+}\right]^{2}}+\frac{1}{\mathrm{~K}_{2} \mathrm{~K}_{3} \mathrm{k}_{4}\left[\mathrm{H}^{+}\right]}+\frac{1}{\mathrm{~K}_{3} \mathrm{k}_{4}}\right\} \\
& +\frac{1}{\mathrm{k}_{4}}
\end{aligned}
$$

A plot of $1 / \mathrm{k}^{\prime}$ vs $1 /\left[\right.$ oxidant] at constant $\left[\mathrm{H}^{+}\right]$(figure 4; $\mathrm{R}^{2}>0.9986$ ) from Eq. 19 yields $1 / \mathrm{k}_{4}$ as

$$
\begin{gathered}
\text { intercept and }\left\{\frac{1}{\mathrm{~K}_{1} \mathrm{~K}_{2} \mathrm{~K}_{3} \mathrm{k}_{4}\left[\mathrm{H}^{+}\right]^{2}}+\frac{1}{\mathrm{~K}_{2} \mathrm{~K}_{3} \mathrm{k}_{4}\left[\mathrm{H}^{+}\right]}\right. \\
\left.+\frac{1}{\mathrm{~K}_{3} \mathrm{k}_{4}}\right\} \text { as slope }
\end{gathered}
$$

From the intercepts of these plots, the values of $\mathrm{k}_{4}$ were found to be $13.3 \times 10^{-4}$ and $58.8 \times 10^{-4} \mathrm{~s}^{-1}$ for CAT and BAT, respectively. Further, the values of protonation constants $\mathrm{K}_{1}$ and $\mathrm{K}_{2}$ were determined by potentiometric titration ${ }^{26}$ and were found to be $13.8 \times 10^{3}$

\begin{tabular}{|c|c|c|}
\hline \multirow[b]{2}{*}{ Temperature (K) } & \multicolumn{2}{|c|}{$10^{4} \mathrm{k}_{4} \mathrm{~s}^{-1}$} \\
\hline & CAT & BAT \\
\hline 293 & 6.66 & 33.3 \\
\hline 298 & 10.1 & 45.5 \\
\hline 303 & 13.3 & 58.8 \\
\hline 308 & 20.0 & 83.3 \\
\hline 313 & 25.0 & 111 \\
\hline $\mathrm{E}_{\mathrm{a}}\left(\mathrm{kJ} \mathrm{mol}^{-1}\right)$ & 44.6 & 35.6 \\
\hline$\Delta \mathrm{H}^{\neq}\left(\mathrm{kJ} \mathrm{mol}^{-1}\right)$ & $42.1 \pm 0.01$ & $33.1 \pm 0.01$ \\
\hline$\Delta \mathrm{G}^{\neq}\left(\mathrm{kJ} \mathrm{mol}^{-1}\right)$ & $90.9 \pm 0.23$ & $87.3 \pm 0.3$ \\
\hline$\Delta \mathrm{S}^{\neq}\left(\mathrm{JK}^{-1} \mathrm{~mol}^{-1}\right)$ & $-161 \pm 0.10$ & $-178 \pm 0.17$ \\
\hline $\log A$ & 7.43 & 10.3 \\
\hline
\end{tabular}
and $8.1 \times 10^{3} \mathrm{M}^{-1}$, for CAT and BAT, respectively. Furthermore the values of $\mathrm{K}_{3}$ for CAT and BAT were determined as $0.96 \times 10^{3}$ and $1.08 \times 10^{3} \mathrm{M}^{-1}$.
Table 3. Effect of varying temperature on the reaction rate and activation parameters with respect to rate - limiting steps for the oxidation of BSZ with CAT and BAT in acid medium.

$[\text { Oxidant }]_{0}=1.0 \times 10^{-3} \mathrm{M} ;[\mathrm{BSZ}]_{0}=1.0 \times 10^{-4} \mathrm{M}$; $\left[\mathrm{HClO}_{4}\right]=4.0 \times 10^{-4} \mathrm{M}$.

Since, the rate was fractional order in [oxidant $]_{0}$, the effect of [oxidant $]_{0}$ on the rate at different temperatures was carried out. Using Eq. (19), from the plots of $1 / \mathrm{k}^{\prime}$ vs $1 /$ [oxidant], values of $\mathrm{k}_{4}$ were calculated at different temperatures for both CAT and BAT. Using these $\mathrm{k}_{4}$ values, activation parameters such as energy of activation $\left(\mathrm{E}_{\mathrm{a}}\right)$, enthalpy of activation $\left(\Delta \mathrm{H}^{\#}\right)$, entropy of activation $\left(\Delta S^{\#}\right)$, free energy of activation $\left(\Delta G^{\#}\right)$ and pre-exponential factor $(\log \mathrm{A})$ for the rate-limiting steps were deduced. All these results are tabulated in table 3 .

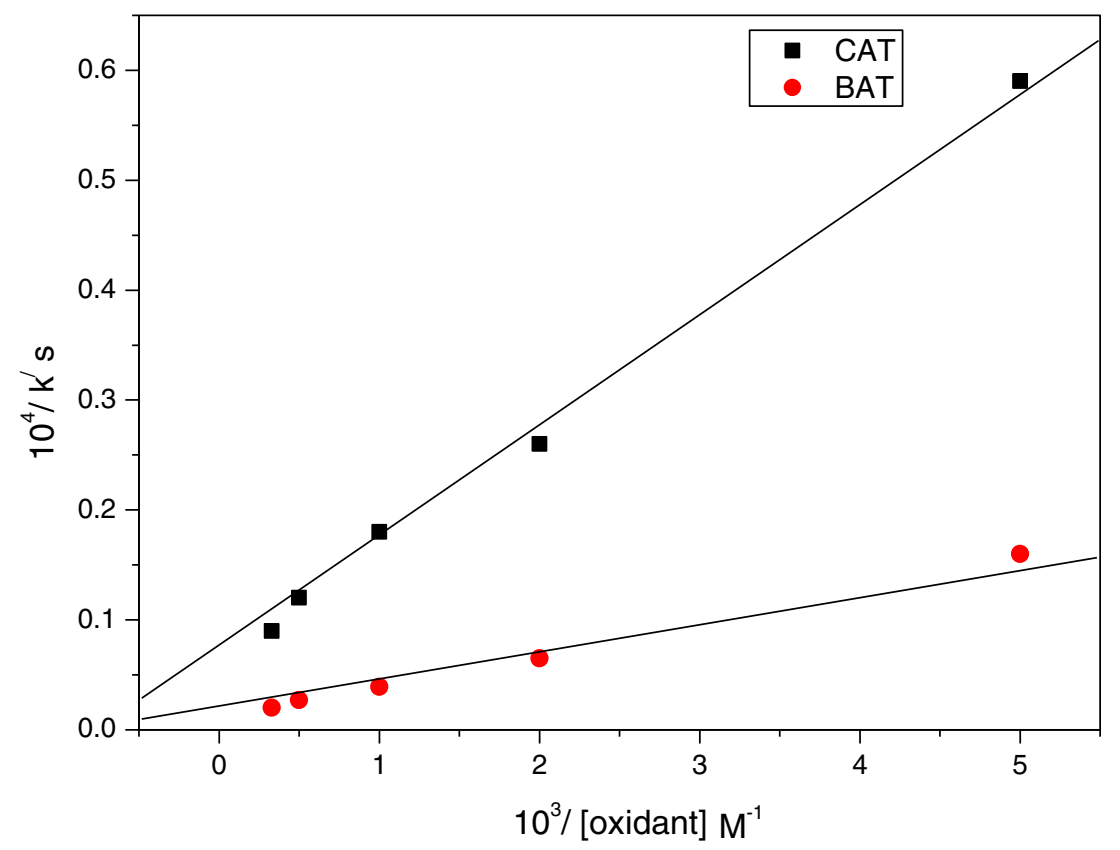

Figure 4. Plots of $1 / \mathrm{k}^{/}$vs $1 /[$ oxidant]. 
(i)<smiles>[Y]C(C)(C)[In]c1ccc(N=Nc2ccc(C(=O)NCCC(=O)O)cc2)c(C(=O)O)c1</smiles>
BSZ dianion $\left(\mathrm{S}^{2-}\right)$

(ii)<smiles>[M]C=CC</smiles>

$\left(\mathrm{SH}_{2}\right)$

(iii)

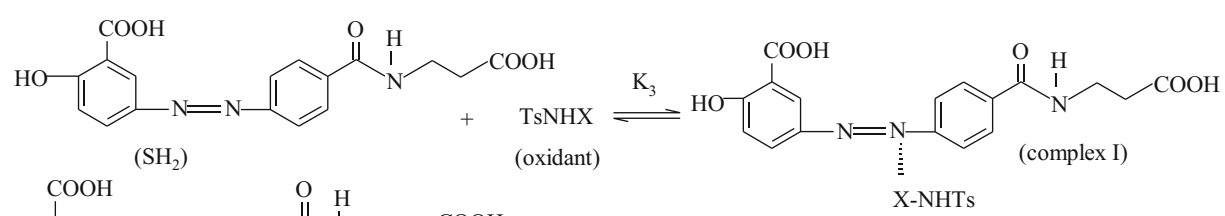

(iv)<smiles>[Y4]NC(=O)N=Nc1ccc(C(=O)O)cc1</smiles><smiles>[X][C@](CC)(N(O)c1ccc(C(=O)NCCC(=O)O)cc1)N(O)c1ccc(C(=O)O)c(C(=O)O)c1</smiles><smiles>OCCCCCO</smiles><smiles>CC(C(=O)O)=C1C=CCC1</smiles><smiles>CC(/C=C/O)N1C=C(c2ccc(C(=O)NCCC(=O)O)cc2)N(C)C1</smiles>

(v)<smiles>O=C(O)CCN(CCC(=O)O)C(=O)c1ccc(N(O)N(O)c2ccc(O)c(C(=O)O)c2)cc1</smiles>

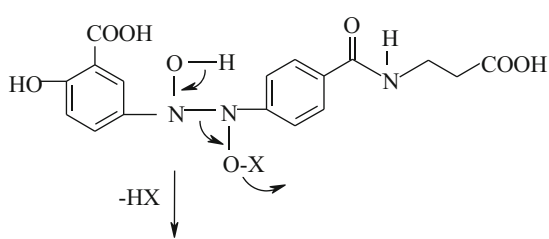<smiles>O=Nc1ccc(O)c(C(=O)O)c1</smiles>
benzoic acid)<smiles>O=Nc1ccc(C(=O)NCCC(=O)O)cc1</smiles>

Scheme 2. A detailed mechanistic interpretation of oxidation for the BSZ with CAT/BAT in acid medium.

The proposed scheme and the derived rate law are substantiated by the experimental observations discussed below.

The negative dielectric effect observed in the present studies $^{27-32}$ clearly supports the dipole-dipole interaction reported (Scheme 2). The negligible effect of ionic strength on the rate of the reaction ${ }^{33}$ clearly indicates that non-ionic species are involved in the rate-limiting step as can be seen in Scheme 2.

\subsection{Comparison of CAT and BAT reactivities}

A comparison of the rates of reaction of CAT and BAT shows that the oxidation of BSZ is about five-fold faster in BAT compared with that of CAT, under identical set of experimental conditions. It is endorsed by the relative magnitudes of activation energies (table 3 ). This trend may be attributed to the difference in electrophilicities of the halocations, $\mathrm{Cl}^{+}$and $\mathrm{Br}^{+}$ions, involved in the 
oxidation process, values of $\mathrm{K}_{3}$ and is also related to the ease with which these species are generated in reactions. In these oxidation reactions, the electronegativity values of $\mathrm{Br}^{+}$and $\mathrm{Cl}^{+}$play a vital role. Bromine has the electronegativity of 2.7 , whereas for chlorine it is 2.8. As the electronegativity increases, the electropositive nature decreases. Further, this trend is also due to more value of $\mathrm{K}_{3}$ for BAT $\left(1.08 \times 10^{3} \mathrm{M}^{-1}\right)$ in comparison with that of CAT $\left(0.96 \times 10^{3} \mathrm{M}^{-1}\right)$. Therefore, the reactivity of BAT is more when compared with CAT. This trend may also be due to the moderate difference in the van der Waals radii of bromine and chlorine. A similar behaviour has been noted in the oxidation of several other substrates with CAT and BAT. ${ }^{34-37}$ The facts furnished in this research and the literature reports led us to conclude that BAT is a stronger oxidant than CAT.

\subsection{Activation parameters}

The proposed mechanism is also supported by the moderate values of energy of activation and other thermodynamic parameters (table 3 ). The energy of activation is the highest for the slowest reaction and vice-versa, indicating that the reaction is enthalpy controlled. The negative values of $\Delta S^{\#}$ indicate a greater degree of ordering in the transition state than in the initial state, due to an increase in solvation during the activation process. Further, the closeness values of $\Delta G^{\#}$ signify that the same type of reaction mechanism could be operative for the oxidation of BSZ with both CAT and BAT in acid medium. The values of frequency factor (A) specify the frequency of collisions and the orientation of reacting molecules.

\section{Conclusions}

The kinetics of oxidation of BSZ with CAT and BAT in acidic $\left(\mathrm{HClO}_{4}\right)$ medium follows the identical kinetics with a rate law $-\mathrm{d}[$ oxidant] $/ \mathrm{dt}=\mathrm{k}$ [BSZ] [oxidant] ${ }^{\mathrm{x}}\left[\mathrm{H}^{+}\right]^{\mathrm{y}}$, where $\mathrm{x}$ and $\mathrm{y}$ are less than unity. 2-hydroxy-5-nitroso-benzoic acid and 3-(4nitroso-benzoylamino)-propionic acid are identified as the oxidation products of BSZ. Thermodynamic parameters and reaction constants were deduced. In the proposed mechanism, TsNHX is assumed to be the reactive species, which interacts with the substrate. The relevant rate law has been deduced. Under identical set of experimental conditions, the rate of oxidation of BSZ is about five-fold faster with BAT than with CAT.

\section{Acknowledgements}

Authors gratefully acknowledge the VGST, Govt. of Karnataka, India for the CESEM award grant No. 24 (2010-11). We are also thankful to Prof. M.A. Pasha and the anonymous reviewer for their valuable suggestions.

\section{References}

1. Sweetman S C 2002 In Martindale: The Complete Drug Reference 33rd edn. (U K: Pharmaceutical Press)

2. Muijsers R B R and Goa K L 2002 Drugs 621689

3. Hussain R N, Ajjan R A and Riley S A 2000 British. $J$. Clin. Pharmacol. 4323

4. Ananda kumar K,Varadharajan K, Ayyappan T, Nageswara Rao P and Sujatha K 2008 Research J. Pharm. Tech. 1472

5. Kaja R K, Surendranath K V, Radhakrishanand P, Satish J and Satyanarayana P V V 2009 Chromatographia 69 1007

6. Mandhanya M, Nithin Dubye, Nidhi Dubey, Sharma P S and Hardenia 2011 Asian. J. Pharma. Med. Sci. 113

7. Campbell M M and Johnson G 1978 Chem. Rev.78 65

8. Bremner D H 1986 Synth. Reagents 69

9. Banerji K K, Jayaram B and Mahadevappa D S 1987 J. Sci. Ind. Res. 4665

10. Agarwal M C and Upadhyay S K 1990 J. Sci. Ind. Res. 4913

11. Armesto X L, Canle L, Garia M V and Santaballa J A 1998 Chem. Soc. Rev. 27453

12. Geethanjali A 2005 Synlet 182857

13. Kolaveri E and Ghorbeni-Choghamarani A 2007 J. Iran Chem. Soc. 2126

14. Jagadeesh R V and Puttaswamy 2013 In Encyclopedia of Reagents for organic synthesis. Chloramine-T: Second update. RC056 9

15. Nair C G R, Kumari R L and Indrasenan P 1978 Talanta 27525

16. Puttaswamy, Jagadeesh R V and Gowda N M M 2005 Int. J. Chem. Kinet. 37700

17. Obeid A A 2009 Rasay. Jour. 2786

18. Puttaswamy and Shubha J P 2009 AIChE Jour. 553234

19. Anu Sukhdev and Puttaswamy 2012 Bull. Korean Chem. Soc. 333544

20. Morris J C, Salazar J A and Wineman M A 1948 J. Am. Chem. Soc. 702036

21. Akerloff G 1932 J. Chem. Soc. $\mathbf{5 4} 4125$

22. Bishop E and Jennings V J 1958 Talanta 1197

23. Murthy A R V and Rao B S 1952 Proc. Ind. Acad. Sci. 3569

24. Pryde B G and Soper F G 1962 J. Chem. Soc. 1582

25. Hardy F F and Johnston J P 1973 J. Chem. Soc. Perkin Trans II 742

26. Sari N and Gurkan P 2004 Z. Naturforsch 59b 692

27. Moelwyn-Hughes E A 1961 In Physical Chemistry $2^{\text {nd }}$ edn. (New York: Pergamon)

28. Bensen S W 1960 In The foundation of Chemical Kinetics (New York: McGraw-Hill)

29. Frost A A and Pearson R G 1961 In Kinetics and Mechanism $2^{\text {nd }}$ edn. (New York: Wiley)

30. Laidler K J 1963 In Reaction Kinetics (New York: Pergamon) 
31. Amis E S 1966 In Solvent effects on reaction rates and mechanism (New York: Academic Press)

32. Reichardt C 2003 In Solvent and solvent effects in organic chemistry $3^{\text {rd }}$ edn. (New York: Wiley)

33. Maron S H and Prutton C F 1972 In Principles of physical chemistry $4^{\text {th }}$ edn. (New Delhi: Oxford-IBH Publisher)
34. Puttaswamy, Mahadevappa D S and Rangappa K S 1989 Bull. Chem. Soc. Jpn. 623343

35. Rangappa K S 2004 J. Indian Chem. Soc. 811025

36. Puttaswamy, Anuradha T M, Ramachandrappa R and Gowda N M M 2000 Int. J. Chem. Kinet. 32221

37. Puttaswamy and Jagadeesh R V 2005 Applied Catal. A: General 292259 